\author{
Asian Journal of \\ Medical and Biological Research \\ ISSN 2411-4472 (Print) 2412-5571 (Online) \\ www.ebupress.com/journal/ajmbr
}

\title{
Article \\ Determination of antibiotics sensitivity profiles of bacteria isolated from raw milk
}

\author{
MuktaTalukder $^{1}$ and H. M. Manir Ahmed ${ }^{2 *}$ \\ ${ }^{1}$ BRAC Dairy and Food Project, Laxmipura Teen Sarak, Joydevpur, Gazipur, Bangladsh \\ ${ }^{2}$ Danish Condensed Milk Bangladesh Limited, Shimrail, Siddirgonj, Narayangonj, Bangladesh
}

*Corresponding author: H. M. Manir Ahmed, PhD, Danish Condensed Milk Bangladesh Limited, Shimrail, Siddirgonj, Narayangonj, Bangladesh. E-mail: manir.astec@gmail.com

Received: 09 August 2016/Accepted: 20 September 2016/ Published: 29 September 2016

\begin{abstract}
The extensive progress of dairy sectors in a developing country like Bangladesh, led to widespread use of antibiotics to improve the health and productivity of animals. Prolonged usage may lead to antibiotic residues in foods of animal origin; hence, the emergence of antimicrobial resistant microorganisms. Accurate data on the antibiotic usage in livestock treatment, antibiotic residues and antimicrobial resistances in raw milk in Bangladesh are lacking. This study aimed to investigate the types and usages of antibiotics in cattle, their potential microbial resistances in raw milk samples. To do so, a total of 54 raw milk samples were evaluated and the bacterial isolates were identified and measured for resistance to 4 antibiotics most commonly used during bacterial infection Bangladesh. Amongst all 54 (100\%) isolates were positive to S. aureus and 36 (66.67\%) isolates were positive to $E$ coli. Determination of the antibiotic resistance pattern of isolates showed that all isolates of $S$. aureus were resistant to cefoxitin (81.48\%), ampicillin (64.81\%), ciprofloxacin (51.85\%), and gentamycin $(70.37 \%)$. E. coli showed resistance to cefoxitin (69.44\%), ampicillin (83.33\%), ciprofloxacin (77.78\%), and gentamycin (86.11\%). However multidrug resistance pattern was also found. The obtained results provide evidence that antimicrobial resistant strains of the above pathogens have become remarkably widespread in raw milk. This requires better management for antibiotic usages among livestock farmers to control sources of food contamination and reduce the health risks associated with the development of resistant microbial strains
\end{abstract}

Keywords: antibiotics; resistance; susceptibility; bacteria; milk

\begin{abstract}
1. Introduction
Antibiotics, the microbiologically produced composites, are used in humans to treat or prevent certain diseases initiated by infectious agents. Nevertheless, the major antibiotics used for humans either belong to the same general classes or have the identical mode of action as those used for animals (Joshi, 2002). The most frequently used antibiotics in livestock among major Bangladeshi dairy farmers are Gentamicin, Ciprofloxacin, Ampicillin and Cefoxitin which belong to the Aminoglycoside, Fluroquinolone, Penicillin and Cephalosphorin groups of antibiotics respectively. It is also worth mentioning that the precise amounts of antibiotics used by farmers in livestock production in Bangladesh are not acknowledged since they are not planned. These antibiotics are generally used to treat respiratory, urinary tract, gastrointestinal, and abdominal infections, including Gram-negative (Escherichia coli, Haemophilus influenzae, Klebsiella pneumoniae, , Proteus mirabilis, and Pseudomonas aeruginosa), and Gram-positive (methicillin-sensitive and methicillin-resistant Staphylococcus aureus, Streptococcus pneumoniae, Staphylococcus epidermidis, Enterococcus faecalis, and Streptococcus pyogenes) bacterial(Dutta et al., 2013). The foremost global public concern and health hazard related with antibiotic residues is the development of the antimicrobial resistant bacterial strains of animal origin and its consequential effect on human health (Threlfall, 2002; Aarestrup, 2006) regarding the efficacy of antimicrobial therapy (Casadevall, 1996). According to Prescott and Baggot (1993), microbial resistance to
\end{abstract}


aminoglycosides, particularly Streptomycin, Neomycin, and Kanamycin is very common and pathogens present in the milk mainly $S$. aureus, E. coli $\mathrm{O} 157: \mathrm{H} 7$ and L. monocytogenes may easily develop antimicrobial resistance (Seeliger and Jones, 1986; Peles et al., 2007). Isolates of S. aureus are frequently resistant to methicillin and essentially all other $\beta$-lactam antibiotics. An organism with this type of resistance is referred to as methicillin-resistant $S$. aureus or MRSA (Lee, 2003). MRSA strains have been isolated in many countries from cows' or small ruminants' milk and various dairy products (Turutoglu et al., 2006; Juhasz-Kaszanyitzky et al., 2007; Normanno et al., 2007; Ateba et al, 2010; Hata et al., 2010; Spanu et al., 2010; Vyletelova et al., 20011; Nam et al., 2011; Ünal et al., 2012). Concerning all these kinds of adverse effects the present study aimed to isolate bacteria from milk obtained from different areas of Bangladesh and further characterization of their resistance and susceptibility patterns to selected antibiotics as well as to evaluate the prevalence of multidrug resistant of bacteria in milk.

\section{Materials and Methods}

\subsection{Sample collection}

A total of 54 raw milk samples were collected for microbial analysis from different areas of Bangladesh during the period of January to April, 2016. About $100 \mathrm{ml}$ of fresh raw milk samples were collected in a sterile sample container using a sample collector ice box at $4{ }^{\circ} \mathrm{C}$ and were transported to the laboratory without delay.

\subsection{Isolation and enumeration of bacteria}

The bacterial count was performed by standard plate count method (ICMSF, 1986). The microbiological conditions of safety and hygiene were then assessed using the methods recommended by International Commission on Microbiological Specifications for Foods (ICMSF, 1986). Serial dilutions of samples were made up to 10-7 in sterile normal water. Bacterial count was carried out by the spread plate technique. The sample $(0.1 \mathrm{ml})$ of each dilution was taken onto each sterile petridish and evenly spread on different culture medium and incubated at $37{ }^{\circ} \mathrm{C}$ for 24 hours. Total viable count (TVC), total coliform count (TCC) and total staphylococcal count (TSC) were done for enumeration using Standard Plate count agar, MacConkey Agar and Mannitol Salt Agar respectively. Bacterial isolates were then identified according to the Bergey's manual of determinative bacteriology (Buchanan and Gibbon, 1984).

\subsection{Study of antibiogram}

The in vitro susceptibility and resistance of the isolated organisms from Mac conkey and Mannitol Salt agar against different antibiotics was measured by the Kirby-Bauer method (Bauer et al., 1966; Marjan et al., 2014). In this study four commonly available antibiotics such as ciprofloxacin (CIP, $5 \mu \mathrm{g})$, Gentamycin $(\mathrm{CN}, 10 \mu \mathrm{g})$,

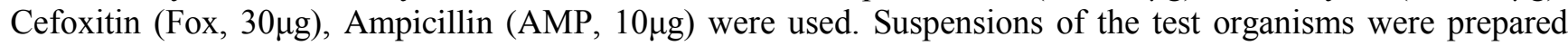
using Muller-Hinton broth by adjusting the turbidity of the broth with normal saline to match the equivalent turbidity standard of McFarland (0.5 standards) and was incubated for 2 hours. Sterile cotton swabs were dipped into the suspensions and the swabs were then evenly spread over the entire surface of a Muller-Hinton agar plate to obtain uniform inoculums. Antibiotic discs of appropriate concentrations were applied aseptically over the surface of the inoculated plates at appropriate spatial arrangement by means of sterile needle within a distance of $5 \mathrm{~mm}$. Plates were then inverted and incubated at $37^{\circ}$ for 14 hours. The diameters of the zones of complete inhibition were measured to the nearest whole millimeter using zone inhibition scale. Zones of inhibition for individual antimicrobial agents were translated into susceptible, intermediate and resistant categories by referring the recommended NCCLS interpretative standards (NCCLS, 2002).

\section{Results and Discussion}

In total 54 raw milk samples were collected. Out of them 54 samples were found positive for $S$. aureus and 36 samples were found positive for $E$. coli which were identified phenotypically based on colony characteristics (Table 1) and biochemical properties (Table 2).The experimental result of raw milk (100\%) samples revealed that all the samples were contaminated with. S. aureus. Several studies have indicated the assortment of pathogenic bacteria especially staphylococcus spp. may rise in raw milk and cheese samples may responsible for the nausea, vomiting, abdominal cramps and diarrhea like diseases (Balaban and Rasooly 2000; Omori et al., 2001; Aly and Galal, 2002; Robinson, 2002; Soomro et al., 2002; Lues et al., 2003; Soomro et al., 2003; Chye et al., 2004; Marjan et al., 2014). The identification of coliform bacteria, such as E. coli, in raw milk is a common indicator of fecal contamination. Their presence in raw milk generally related with fecal contamination of water sources or unhygienic practices during milking process. Irregular bathing of animal, feeding of animal in low land, muddy cow yard, unsanitary milking utensil and contamination of body surface by feces could also 
act as critical factors. Higher prevalence of E. coli was recounted by many authors. In Malaysia Yuen et al. (2012) found the presence of $E$. coli in $47 \%$ of raw milk samples. In India Pant et al. (2013) found E. coli in $100 \%$ raw milk samples. Lower coliform count than this study was found in Uddin et al. (2011). E. coli normal flora is supposed to be harmless. But some pathogenic strains of E. coli can cause gastroenteritis, urinary tract infection as well as diarrhea in infants. Although this study found $36(66.67 \%)$ samples positive for $E$ coli. which was very close to above research findings

To find out antibiotic susceptibility, total 4 antibiotics were tested against 54 isolates of $S$. aureus and 36 isolates of Escherichia coli. The tested antibiotics were divided into mainly two group G-I (Cell wall synthesis inhibitor) and G-II (Protein synthesis inhibitor) (Tables 3 and 4).

The strain of $S$. aureus (Table 3) signifies that only $16.67 \%$ isolates showed susceptibility against Ampicillin. It was followed by Cefoxitin and Gentamycin; whereas $11.11 \%$ and $18.52 \%$ isolates showed susceptibility against these two antibiotics. The highest sensitivity found only in case of Ciprofloxacin which was $20.37 \%$. On the contrary the highest resistance of $S$. aureus isolates found in case of Cefoxitin $81.48 \%$ and this resistance followed to other antibiotics; $64.81 \%, 51.85 \%$ and $70.37 \%$ isolates showed resistance against Ampicillin, Ciprofloxacin and Gentamycin respectively. Figure 1 shows the antibiotic resistance pattern and multidrug resistance results in the tested isolates of $S$. aureus. It shows that all the isolates of $S$. aureus were resistant to two or more of four antibiotics used here. Among 56 isolates of $S$. aureus all of them were multidrug resistant but showing their resistance patterns differently for different. One thing the present study reflects that approximately $81.48 \%$ S. aureus isolates showed resistance against cefoxitin antibiotic (Table 3). Cefoxitin is one of the indicators of identification of Methicillin resistant S. aureus (MRSA). Occurrence of Methicillin resistant $S$. aureus in food samples has been a chief concern worldwide (Shanebandi et al., 2014). Additionally, the presence of MRSA may be considered as indicator of resistance of the isolates against the other $\beta$-lactam antibiotics (Enright et al., 2002; Naimi, 2003; Zinke et al., 2012; Shanebandi et al., 2014). The strain E. coli represents that only $8.3 \%$ isolates showed sensitivity against Ampicillin (Table 4). It was followed by Ciprofloxacin and Gentamycin; only 5.56\% isolates showed sensitivity against these two antibiotics. The highest sensitivity found only in case of Cefoxitin which was $22.22 \%$. Among 36 E. coli isolates, $86.11 \%$ exhibited resistance against Gentamycin. However, same percentage of isolates showed resistance against Ampicillin. Percentage of intermediate isolates remained within 8-17\% for almost all the antibiotics tested. This result finds similarity with Afroz et al. (2013), which isolated E. coli showing high resistance against Gentamycin $(88 \%)$ in antibiotic susceptibility test. Figure 2 showed the antibiotic resistance pattern and multidrug resistance results in the tested isolates of $E$. coli. It shows that all the isolates of $E$. coli were resistant to two or more of four antibiotics used here. Among 36 isolates of E. coli, all of them were multidrug resistant but showing their resistance patterns differently for different antibiotics. However, results of this study differ from a previous study of Islam et al. (2010) who found only 3.12\% isolates to be MDR but the findings of Nipa et al. (2011) who showed $98.06 \%$ isolates to be MDR, has a close proximity with present study.

In developing countries like Bangladesh more than $70 \%$ of infecting bacteria have been accounted as multi drug resistant strain (MDR) (Prescott, 2000; Jilani et al., 2008; Dutta et al., 2013). However, one of our research individuals reported multi drug resistant bacteria isolated from the milk and milk products (Marjan et al., 2014). Prevalence of such a large amount of MDR bacteria in food samples is a hurdle to develop a healthy and safe living environment for human.

Table1. Isolation of bacteria (colony characteristics).

\begin{tabular}{ll}
\hline Organism & Colony characteristics \\
\hline Staphylococcus aureus & Distinctly white color and lemon yellow color in MannitolSaltagar were studied \\
& $\begin{array}{l}\text { separately. } \\
\text { Escherichia coli }\end{array}$ \\
Red colonies surrounded by a precipitation zone.
\end{tabular}

Table 2. Identification of bacteria (biochemical test).

\begin{tabular}{|c|c|c|c|c|c|c|c|c|c|c|c|}
\hline Isolates & & & & TSI & & & & MIU & & MR & VP \\
\hline & But & Slant & $\mathrm{H}_{2} \mathrm{~S}$ & Gas & Citrate & Catalase & Motility & Ind & Ura & & \\
\hline E. coli & A & $\mathrm{K}$ & - & + & - & - & + & + & - & + & - \\
\hline S. aureus & - & - & - & - & + & + & - & - & + & + & + \\
\hline
\end{tabular}

Note: $\mathrm{A}=$ Acidic, $\mathrm{K}=$ Alkaline, MR=Methyle red, VP=Voges-Proskaur, TSI= Triple Sugar Iron, MIU= Motility Indole Urease, Ind $=$ Indole, Ura $=$ Urease 
Table 3. Antibiotic sensitivity profile of $S$. aureus isolates (\%).

\begin{tabular}{lcclc}
\hline Sensitivity & \multicolumn{2}{c}{ G-I (Cell wall synthesis } & \multicolumn{2}{c}{$\begin{array}{c}\text { G-II (Protein synthesis } \\
\text { inhibibitor) }\end{array}$} \\
\hline & AMP & FOX & CIP & CN \\
$\mathrm{R}$ & 64.81 & 81.48 & 51.85 & 70.37 \\
$\mathrm{I}$ & 18.51 & 7.41 & 27.78 & 11.11 \\
$\mathrm{~S}$ & 16.67 & 11.11 & 20.37 & 18.52 \\
\hline
\end{tabular}

Note: AMP=ampicillin, $\mathrm{CN}=$ gentamycin, FOX= cefoxitin, CIP-ciprofloxacin, R-resistance, I-Intermediate, S-Susceptible

Table 4. Antibiotic sensitivity profile of $E$. coli isolates (\%).

\begin{tabular}{llc|lc}
\hline Sensitivity & \multicolumn{1}{c|}{$\begin{array}{c}\text { G-I (Cell wall synthesis } \\
\text { inhibitor) }\end{array}$} & \multicolumn{1}{c}{$\begin{array}{c}\text { G-II (Protein synthesis } \\
\text { inhibitor) }\end{array}$} \\
\hline & AMP & FOX & CIP & CN \\
$\mathrm{R}$ & 83.33 & 69.44 & 77.78 & 86.11 \\
$\mathrm{I}$ & 8.33 & 8.33 & 16.67 & 8.33 \\
$\mathrm{~S}$ & 8.33 & 22.22 & 5.56 & 5.56 \\
\hline
\end{tabular}

Note: AMP=ampicillin, $\mathrm{CN}=$ gentamycin, FOX= cefoxitin, CIP-ciprofloxacin, R-resistance, I-Intermediate, S-Susceptible

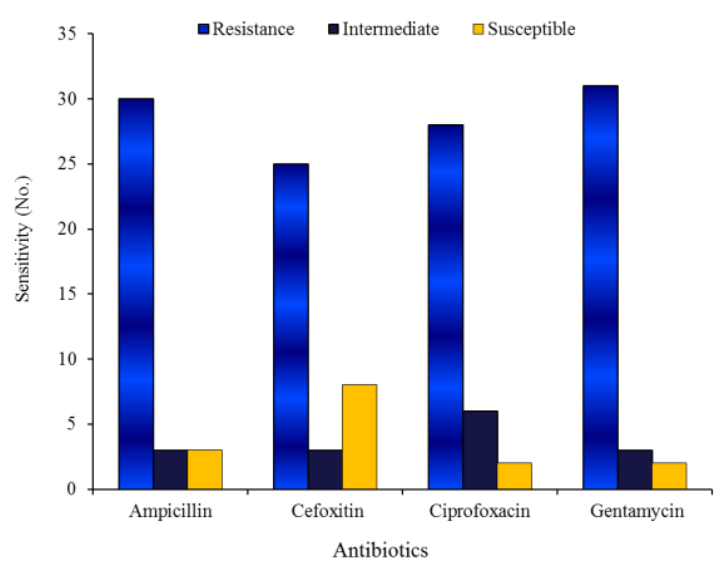

Figure 1. Antibiotic sensitivity profile of S. aureus against commonly used antibiotics in Bangladesh.

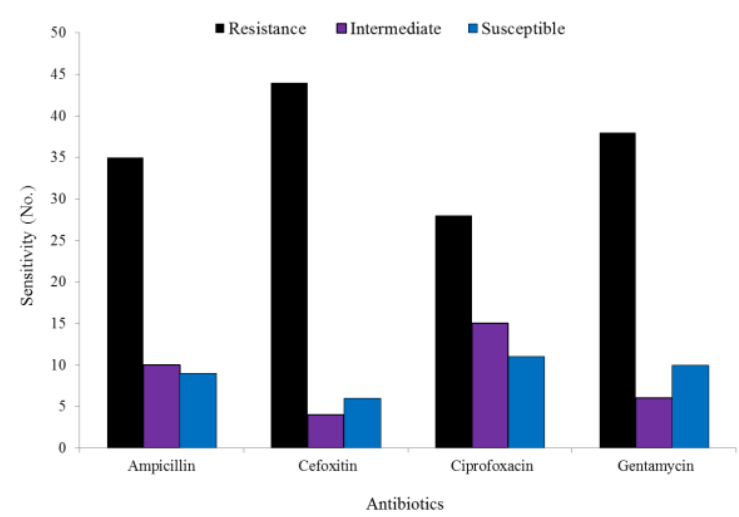

Figure 2. Antibiotic sensitivity profile of Escherichia coli against commonly used antibiotic in Bangladesh

\section{Conclusions}

The present study gives us a redirection to the sensitivity profiles of $S$. aureus and $E$ coli isolated from milk samples against four commonly used antibiotics in Bangladesh and also depict the multi-drug resistance of same bacterial isolates in a variety of milk samples which ultimately give a point to indiscriminate use of antibiotics in dairy field. And it is a great matter of concern for human health also because we are the people who consume these animal products. Moreover these multidrug resistant bacteria may no longer be treated with conventional 
therapeutic drugs and they are also capable of spreading their resistant gene to other bacterial genera. So, frequent use of antibiotics should be prohibited. And government should give a concern on that.

\section{Conflict of interest}

None to declare.

\section{References}

Aarestrup FM, 2006. Antimicrobial resistance in bacteria of animal origin, ASM Press, Washington DC.

Afroz H, F Sultana, M Fakruddin, Kamrunnahar, ZUM Khan and S Datta, 2013. Isolation of Escherichia coli and Staphylococcus aureusfrom full cream powder milk sold under market conditions at Dhaka, Bangladesh and their antibiotic susceptibility. J. Advan. Sci. Res.,4:27-31.

Aly SA and EA Galal, 2002. Effect of milk pretreatment on the keeping quality of dominate cheese. Pak. J. Nutr., 1:132-136.

Ateba CN, M Mbewe, MS Moneoang and CC Bezuidenhout, 2010. Antibiotic-resistant Staphylococcus aureus isolated from milk in the Mafikeng Area, North West province, South Africa. South. Afri. J. Sci., 106:1-6.

Balaban N and A. Rasooly, 2000. Staphylococcal enterotoxins. Int. J. Food Microbiol., 61:1-10.

Buchanan RE and NE Gibbon, 1984. Bergey`s manual of determinative bacteriology. William and Wilkins Co. Baltimore, New York.

Casadevall A, 1996. Crisis in infectious diseases: time for a new paradigm? Clin. Inf. Dise., 23:790-794.

Chye FY, A Abdullah and MK Ayob, 2004. Bacteriological quality and safety of raw milk in Malaysia. Food.Microbiol., 21:535-541.

Dutta S, MR Hasan, F Rahman MSA Jilani and R Noor, 2013. Study of antimicrobial susceptibility of clinically significant microorganisms isolated from selected areas of Dhaka, Bangladesh. Bang. J. Med. Sci., 12:34-42.

Enomoto M and M Saito, 1972. Carcinogens produced by fungi. Ann. Rev. Microbiol., 26: 279-312.

Enright MC, DA Robinson, G Randle, E Feil, H Grundmann and BG Spratt, 2002.The evolutionary history of methicillin-resistant Staphylococcus aureus (MRSA). Proc. Nat. Acad. Sci. USA., 99:7687-7692.

Hata E, K Katsuda, H Kobayashi, I Uchida, K Tanaka and M Eguchi, 2010. Genetic variation among Staphylococcus aureus strains from bovine milk and their relevance to methicillin-resistant isolates from humans. J. Clin. Microbiol., 48: 2130-2139.

ICMSF, 1986. Sampling for microbiological analysis: Principles and specific applications. Microorganisms in Food, 2nd Edn. Blackwell Scientific Publications, UK.

Islam A, RM Mazumdar, M Fakruddin,S Islam, MN Nipa, A Iqbal and HR Buiyan, 2010. Multiple resistant bacteria on fruits from different market of Chittagong city in Bangladesh.Bang. Res. Pub., J. 4: 342-350.

Jilani MSA, M Murshed, L Sultana, and Z Hasan, 2008. Common clinically important aerobic bacteria and their antibiotic resistance pattern of Dhaka city and its vicinity. Bang. Med. Coll. J., 14: 66-71.

Joshi S, 2002. HPLC separation of antibiotics present in formulated and unformulated samples. J. Pharma. Biomed. Ana., 28:795-809.

Juhasz-Kaszanyitzky E, S Janosi, P Somogyi, A Dan, L van der Graaf-van Bloois, E van Duijkeren and JA Wagenaar, 2007. MRSA transmission between cows and humans. Emer. Inf. Dis., 13:630-632.

Lee JH, 2003. Methicillin (oxacillin)-resistant Staphylococcus aureus strains isolated from major food animals and their potential transmission to humans. Appl. Environ. Microbiol., 69:6489-6494.

Lues JFR, P Venter and H van der Westhuizen, 2003. Enumeration of potential microbiological hazards in milk from a marginal urban settlement in central South Africa. Food. Microbiol., 20: 321-326.

Marjan S, KK Das, SK Munshi and R Noor, 2014. Drug-resistant bacterial pathogens in milk and some milk products. Nutr.Food. Sci., 44:241-248

Naimi TSH, K Como-Sabetti, SM Borchardt, DJ Boxrud, J Etienne, SK Johnson, FVandenesch, S Fridkin, C O'Boyle, RN Danila and R Lynfield, 2003. Comparison of community and health care-associated methicillin-resistant Staphylococcus aureusinfection .J. Am. Med. Associat., 290:2976-2984.

Nam HM, AL Lee, SC Jung, MN Kim, GC Jang, SH Wee and SK Lim, 2011. Antimicrobial susceptibility of Staphylococcus aureus and characterization of methicillin-resistant Staphylococcus aureus isolated from bovine mastitis in Korea. Food Borne. Path. Dis., 8: 231-238.

NCCLS, 2002. Analysis and presentation of cumulative susceptibility test data; approved guideline. NCCLS document M39-A. NCCLS, Wayne, Pa.

Nipa MN, RM Mazumdar, MM Hasan, M Fakruddin, S Islam, HR Bhuiyan and AIqbal, 2011. Prevalence of multi drug resistant bacteria on raw salad vegetables sold in major markets of Chittagong City, Bangladesh. Middle-East J. Sci. Res., 10:70-77. 
Normanno G, M Corrente, GI Salandra, ADambrosio, NCQuaglia, A Parisi, G Santagada, AFirinu, ECrisetti and GV Celano, 2007. Methicillin resistant Staphylococcus aureus (MRSA) in foods of animal origin product in Italy. Int. J. Food. Microbiol., 117: 219-222.

Omori Y, J Imai, M Watanabe, TKomatsu, Y Suzuki, KKataoka, S Watanabe, A Tanigami and S Sugano, 2001. CREB-H: a novel mammalian transcription factor belonging to the CREB/ATF family and functioning via the box-B element with a liver-specific expression. Nucl. Acid. Res., 29: 2154-2156.

Pant RSNirwal and N Rai, 2013. Prevalence of antibiotic resistant bacteria and analysis of microbial quality of raw milk samples collected from different regions of Dehradun. Int. J. Pharm. Tech. Res., 5:804-810.

Peles F, M Wagner, L Varga, I Hein, P Rieck, K Gut- ser, PKeresztúri, G Kardos, I Turcsányi, B Béri and A Szabó, 2007. Characterization of Staphylococcus aureus strains isolated from bovine milk in Hungary. Int. J. Food. Microbiol.,118:186-193.

Prescott JF and ID Baggot, 1993. Antimicrobial Therapy in Veterinary Medicine. Iowa State University Press, Ames.

Prescott JF, 2000. Antimicrobial drug resistance and its epidemiology.In Prescott, J. F., Baggot, J. D. and Walker, R. D. (Eds.). Antimicrobial Therapy in Veterinary Medicine, Ames: Lowa State University Press, Ames. pp. 27-49.

Robinson RK, 2002. The microbiology of milk and milk products. Dairy Microbiology Hand Book, John Wiley and Sons, pp. 765. New York.

Seeliger HPR and D Jones, 1986. Genus Listeria, In: J. G. Holt, Ed., Ber. Man. Syst. Bacteriol., 2:1235-1245.

Shanehbandi D, B Baradaran, S Sadigh-Eteghad and H Zarredar, 2014. Occurrence of methicillin resistant and enterotoxigenicStaphylococcusaureusin traditional cheeses in the north west of Iran. ISRN Microbiol.http://dx.doi.org/10.1155/2014/129580.

Soomro AH, MA Arain, M Khaskheli and B Bhutto, 2002. Isolation of Escherichia coli from milk and milk products in relation to public health sold under market conditions at Tandojam. Pak. J. Nutr.,1:151-152.

Soomro AH, MA Arain, M Khaskheli and B Bhutto, 2003. Isolation of Staphylococcus aureus from milk products sold at sweet meat shops of Hyderabad. Onl. J. Biol. Sci., 3:91-94.

Spanu V, S Virdis, C Scarano, F Cossu, EPL De Santis, AM Cosseddu, 2010. Antibiotic resistance assessment in Staphylococcusaureus strains isolated from raw sheep's milk cheese. Vet. Res.Communit., 34:87-90.

Eickhoff TC, 1992. Antibiotics and Nosocomial Infections," In: J. V. Bennett and P. S. Brachman, Eds., Hospital Infections, 3rd Edition, Little, Brown and Company, Boston, 245-264.

Threlfall EJ, 2002. Antimicrobial drug resistance in Salmonella: problems and perspectives in food- and waterborne infections. FEMS Microbiol. Rev., 26:141-148.

Turutoglu H, M Hasoksuz, DOzturk, MYildirim and S Sagnak, 2009. Methicillin and aminoglycoside resistance in Staphylococcus aureusisolates from bovine mastitis. J. Dairy. Sci., 73:107-114.

Uddin MA, HM Motazzim-ul-Haque and R Noor, 2011. Isolation and identification of pathogenic Escherichia coli, Klebsiellas pp. and Staphylococcus spp. in raw, milk samples collected from different areas of Dhaka city, Bangladesh. Stam. J. Microbiol., 1:19-23.

Unal N, S Askar, HC Macun, F Sakarya, B Altun and M Yıldırım, 2012. Panton-Valentine leukocidin and some exotoxins of Staphylococcus aureus and antimicrobial susceptibility profiles of staphylococci isolated from milks of small ruminants. Trop. Anim. Health. Product., 44:573-579.

Vyletelova M, O Hanus, R Karpiskova and Z Stastkova, 2011. Occurrence and antimicrobial sensitivity in staphylococci isolated from goat, sheep and cow's milk. Acta.Univers. Agric. Silvic. Mend. Brun., 59:209213.

Yuen K, CF Yee and FH Yin, 2012. Microbiological quality and the impact of hygienic practices on the raw milk obtained from the small-scale dairy farmers in Sabah, Malaysia. Int. J. Agric. Food. Sci., 2:55-59.

Zeina K, AK Pamela and S Fawwak, 2013. Quantification of antibiotic residues and determination of antimicrobial resistance profiles of microorganisms isolated from bovine milk in Lebanon. Food.Nutr. Sci., 4:1-9.

Zinke C, M Winter, E Mohr and V Krömker, 2012. Occurrence of methicillin-resistant Staphylococcus aureusin cheese produced in German farm-dairies. Advan. Microbiol., 2: 629-633. 